\title{
Church Acoustics and the Influence of Occupancy
}

\author{
Victor Desarnaulds ${ }^{1}$, António P.O. Carvalho ${ }^{2}$ and Gilbert Monay ${ }^{3}$ \\ ${ }^{1}$ Ecole Polytechnique Fédérale de Lausanne (EPFL), CH-1015 Lausanne, \\ Switzerland (desarnaulds@monay.ch); \\ ${ }^{2}$ Laboratoty of Acoustics, Faculty of Engineering, University of Porto, R. Dr. Roberto \\ Frias, P-4200-465 Porto,Portugal (carvalho@fe.up.pt); \\ ${ }^{3}$ Bureau G. Monay, 25 Vinet, CH-1004 Lausanne, Switzerland (monay@monay.ch)
}

(Received 28 May 2001 and accepted in revised form in 10 October 2001)

\begin{abstract}
Speech intelligibility is usually evaluated, by the use of objective parameters, in unoccupied rooms due to practical considerations. However, under normal conditions, the room occupancy can increase or decrease the values of speech intelligibility by the effect of the additional sound absorption present in the room or by the change in $\mathrm{S} / \mathrm{N}$ ratio. Measurements were carried out in six churches with and without occupancy. The results show that occupancy induces a mean increase for the speech intelligibility of $\triangle S T I$ (STIoccupSTIunoccup) of 0.050 with the use of a public address system (PA) and 0.035 without a PA. This increase is caused mainly by the reduction of the room reverberation time, due to the increased sound absorption and by the reduction of the additional $R T$ induced by the PA (using loudspeakers with strong directivity oriented towards the congregation area). The variations in the speech intelligibility values with occupancy can be predicted in churches by employing new empirical formulations. The decrease in $S / N$ ratio (due to the background sound level augmentation by the presence of people and by sound level decrease with distance in the congregation area), or the poor directivity and orientation of the sound sources, could reduce the speech intelligibility gain in particular cases. Other effects induced by the congregation, such as the variations of humidity and temperature, generally have negligible effect on speech intelligibility.
\end{abstract}

\section{INTRODUCTION}

For reasons of convenience, the measurement of speech intelligibility using objective parameters takes place generally in unoccupied rooms. Under normal conditions of use, the room occupation can increase or decrease the speech intelligibility. The available bibliography concerning the acoustic effect of occupancy, relates primarily to the sound absorption of the audience (to calculate the reverberation time in occupied room see references ${ }^{1-3}$ ) or on the attenuation within the public ${ }^{4,5}$ (in particular the $125-350 \mathrm{~Hz}$ "seat dip attenuation" ${ }^{6-8}$ ).

This paper concerns a study that aims at determining the effect of occupation on 
speech intelligibility based on comparisons made with one speech intelligibility objective parameter measured in unoccupied and occupied churches. The analysis of the various effects induced by the presence of the congregation on the speech intelligibility will result in a proposed a model to determine the variations of objective speech intelligibility according to the church occupancy.

\section{THE VARIOUS EFFECTS OF THE OCCUPANCY ON SPEECH INTELLIGIBILITY}

Speech intelligibility is influenced by many parameters reasonably well accountable in terms of the objective descriptors ${ }^{9}$. Among these parameters, the most significant are the signal-to-noise ratio $(S / N)$, that represents the emergence of the speech level over the background noise, the reverberation time $(R T)$ and the presence of disturbing late reflections.

Certain effects related to the room occupancy can increase the speech intelligibility values, such as:

1. Reduction in the reverberation time induced by the additional sound absorption brought by the audience;

2. Reduction in the reverberation induced by the sound system. In the case of an adapted public address system (loudspeakers with high directivity directed towards the congregation area), the public absorbs a large part of the energy diffused by the loudspeakers, whereas this is sent to all the empty room volume when the church is unoccupied;

3. Reduction in the phenomena of focusing. The public by its sound absorption can remove a possible flutter echo between the floor and the ceiling (especially if this is arched);

4. In winter, the heating of the church during church services (changing the temperature and humidity) induces a reduction in the reverberation time values (by increasing the speed of sound propagation and the air absorption, at low and medium frequencies) as well as a bending downward of the sound rays (positive variation in temperature with height).

Other effects, on the contrary, can decrease the speech intelligibility, such as:

1. Increase in the background noise level related to the presence of the congregation (seating noise, talks, coughing, etc.);

2. The weakening of the sound level with distance within the congregation due to the sound absorption and the effect of shielding.

\section{MEASUREMENT}

\subsection{Method and data description}

In order to cause the least possible disturbance to the congregation during services and to allow the collection of a maximum of information, a measuring system of type MLS (MLSSA) was used with asynchronous data processing (acquisition with two recorders DAT Casio DA-7), except for Oporto's St John Church (measurement with a B\&K 3361 system $^{10}$ ). The data presented in this study relate mainly to the 
speech intelligibility expressed by the STI (Speech Transmission Index ${ }^{9}$ ) as well as the reverberation time $(R T)$. Recording of the services facilitated analysis of the sound levels (in $\mathrm{dBA}, \mathrm{dB}_{\mathrm{Lin}}$ and octave bands from 125 to $4000 \mathrm{~Hz}$ ), the background noise and the various spoken interventions during the proceedings.

The field measurements took place in six churches (unoccupied and occupied) whose main characteristics are given in Table 1.

Table 1. Main characteristics of the churches sampled

\begin{tabular}{lllcc} 
Church (symbol) & Place, country & Denomination & $\begin{array}{c}\text { Volume } \\
\left(\mathrm{m}^{3}\right)\end{array}$ & $\begin{array}{c}\text { Occupation } \\
\text { (persons) }\end{array}$ \\
\hline Sacré-Cour (LC) & La-Chaux-de-Fonds, Switzerland & Catholic & 9137 & 183 \\
\hline Pasquart (P) & Bienne, Switzerland & Protestant & 4472 & 114 \\
\hline Fille-Dieu (FD) & Romont, Switzerland & Catholic & 5600 & 124 \\
\hline Cheseaux (C) & Cheseaux, Switzerland & Protestant & 575 & 53 \\
\hline Romanel (R) & Romanel, Switzerland & Protestant & 477 & 28 \\
\hline St. John (J) & Porto, Portugal & Catholic & 6048 & 200 \\
\hline & & Mean & 4385 & 117 \\
\cline { 2 - 4 } & & Standard dev. & 3365 & 68
\end{tabular}

\subsection{Results}

Tables 2 and 3 present the results for the measured speech intelligibility index and the reverberation time values $(R T)$.

Table 2. STI results for the churches sampled $(\mathbf{P A}=$ Public Address system, DI = Directivity Index $)$

\begin{tabular}{llcccc} 
Church & \multicolumn{1}{c}{ Condition } & STI occup. & STI unocc. & $\begin{array}{c}\Delta \text { STI } \\
\text { STIoccup }- \text { STIunoccup }\end{array}$ & $\begin{array}{c}\text { Standard } \\
\text { deviation }\end{array}$ \\
\hline Sacré-cœur & Without PA & 0.278 & 0.242 & 0.036 & 0.035 \\
& With PA 1 (high DI) & 0.472 & 0.410 & 0.062 & 0.043 \\
& With PA 2 (low DI) & 0.405 & 0.332 & 0.073 & 0.049 \\
\hline Pasquart & Without PA & 0.523 & 0.495 & 0.028 & 0.013 \\
& With PA & 0.576 & 0.558 & 0.018 & 0.029 \\
\hline Fille-Dieu & Without PA & 0.313 & 0.290 & 0.023 & 0.015 \\
\hline Cheseaux & Without PA & 0.515 & 0.449 & 0.066 & 0.019 \\
\hline Romanel & Without PA & 0.615 & 0.577 & 0.038 & 0.012 \\
\hline St. John & Without PA & 0.435 & 0.415 & 0.020 & 0.045 \\
& With PA & 0.555 & 0.508 & 0.048 & 0.029 \\
\hline Mean values & Without PA & $\mathbf{0 . 4 4 7}$ & $\mathbf{0 . 4 1 1}$ & $\mathbf{0 . 0 3 5}$ & $\mathbf{0 . 0 1 4}$ \\
& With PA & $\mathbf{0 . 5 3 4}$ & $\mathbf{0 . 4 9 2}$ & $\mathbf{0 . 0 5 0}$ & $\mathbf{0 . 0 2 4}$
\end{tabular}


Table 3. Reverberation time results for the churches sampled

\begin{tabular}{|c|c|c|c|c|c|c|c|}
\hline \multirow[b]{2}{*}{ Church } & \multirow[b]{2}{*}{ Situation } & \multicolumn{6}{|c|}{ Frequency $(\mathrm{Hz})$} \\
\hline & & 125 & 250 & 500 & 1000 & 2000 & 4000 \\
\hline \multirow[t]{3}{*}{ Sacré-cœur } & Occupied & - & 3.93 & 4.66 & 4.13 & 3.54 & 2.75 \\
\hline & Unoccupied & 3.26 & 5.88 & 6.83 & 6.47 & 5.91 & 4.19 \\
\hline & difference & - & 1.95 & 2.17 & 2.33 & 2.37 & 1.43 \\
\hline \multirow[t]{3}{*}{ Pasquart } & Occupied & 1.58 & 2.14 & 2.32 & 2.25 & 2.24 & 1.71 \\
\hline & Unoccupied & 1.74 & 2.43 & 2.74 & 2.77 & 2.53 & 1.93 \\
\hline & difference & 0.16 & 0.29 & 0.42 & 0.52 & 0.29 & 0.22 \\
\hline \multirow[t]{3}{*}{ Fille-Dieu } & Occupied & 3.00 & 3.80 & 3.50 & 2.80 & 2.60 & 2.10 \\
\hline & Unoccupied & 3.15 & 4.40 & 4.65 & 4.20 & 2.80 & 2.60 \\
\hline & difference & 0.15 & 0.60 & 1.15 & 1.40 & 0.20 & 0.50 \\
\hline \multirow[t]{3}{*}{ Cheseaux } & Occupied & 1.04 & 1.05 & 1.16 & 1.13 & 1.08 & 1.05 \\
\hline & Unoccupied & 1.17 & 1.51 & 1.75 & 1.84 & 1.86 & 1.60 \\
\hline & difference & 0.13 & 0.46 & 0.59 & 0.71 & 0.78 & 0.55 \\
\hline \multirow[t]{3}{*}{ Romanel } & Occupied & 0.69 & 0.83 & 0.89 & 0.87 & 0.86 & 0.75 \\
\hline & Unoccupied & 1.17 & 1.51 & 1.75 & 1.84 & 1.86 & 1.60 \\
\hline & difference & 0.48 & 0.68 & 0.86 & 0.97 & 1.00 & 0.85 \\
\hline \multirow[t]{3}{*}{ St. John } & Occupied & 2.86 & 2.45 & 2.43 & 2.18 & 1.92 & 1.70 \\
\hline & Unoccupied & 3.09 & 3.32 & 3.31 & 3.22 & 2.73 & 2.42 \\
\hline & difference & 0.23 & 0.87 & 0.88 & 1.04 & 0.81 & 0.72 \\
\hline \multirow[t]{3}{*}{ Mean values } & Occupied & 2.1 & 2.3 & 2.5 & 2.2 & 2.0 & 1.7 \\
\hline & Unoccupied & 2.2 & 3.1 & 3.4 & 3.3 & 2.9 & 2.3 \\
\hline & difference & 0.2 & 0.8 & 1.0 & 1.2 & 0.9 & 0.7 \\
\hline
\end{tabular}

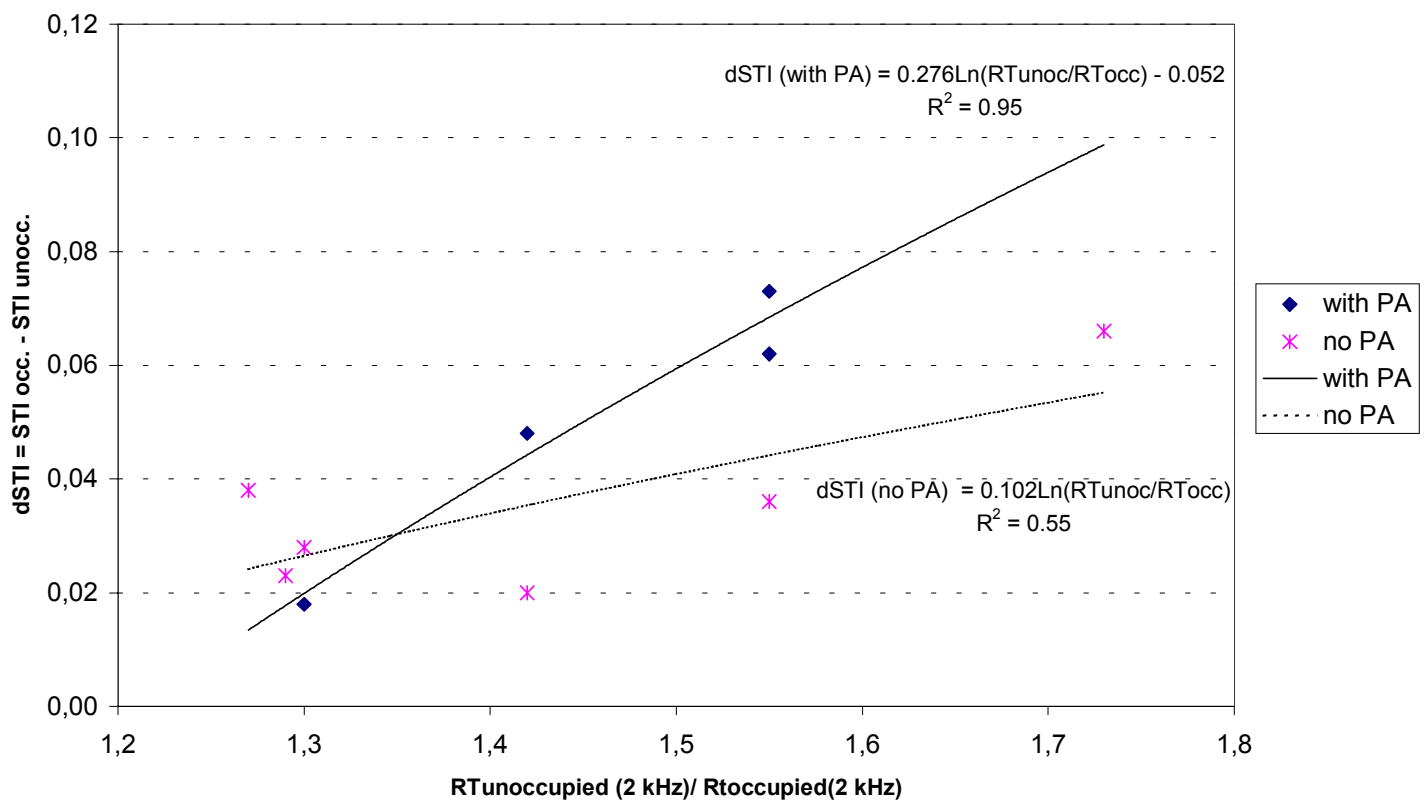

Figure 1. Variations in the $S T I$ mean values in churches (with and without a public address system, PA). 


\section{ANALYSIS}

\subsection{Speech Transmission Index and Reverberation Time}

The $\Delta S T I$ results shown in Table 2 and Figure 1 highlight an increase in the speech intelligibility values with the occupancy. This improvement is more significant when the sound system is used:

$$
\begin{aligned}
\Delta S T I=\text { STIoccup }- \text { STIunoccup } & =0.035 \pm 0.014, \text { without a sound system; } \\
& =0.050 \pm 0.024, \text { with a sound system } .
\end{aligned}
$$

The variation in the speech intelligibility values $(\Delta S T I)$ correlates well with the reduction in the reverberation time values for $2 \mathrm{kHz}$ (or more precisely with the factor: $\ln (R T u n o c c / R T o c c)$ ), and this particularly when the sound system is used (see Figure 1). Without the use of a sound system, the improvement of the speech intelligibility increases slightly with the reduction in the reverberation time.

The reverberation time measurements show a reduction in the RT values with occupancy from 0.13 to 2.37 seconds, strongly dependent on the frequency band (average of $0.8 \pm 0.6$ seconds for a 95\% confidence interval) (Table 3). Church occupancy induces a significant decrease in the reverberation time values, particularly in the $1 \mathrm{kHz}$ and $2 \mathrm{kHz}$ frequency bands, which are some of the most significant in terms of speech intelligibility quality (see Table 3 and Figure 2). This decrease in the $R T$ values can be explained by several effects as described below.

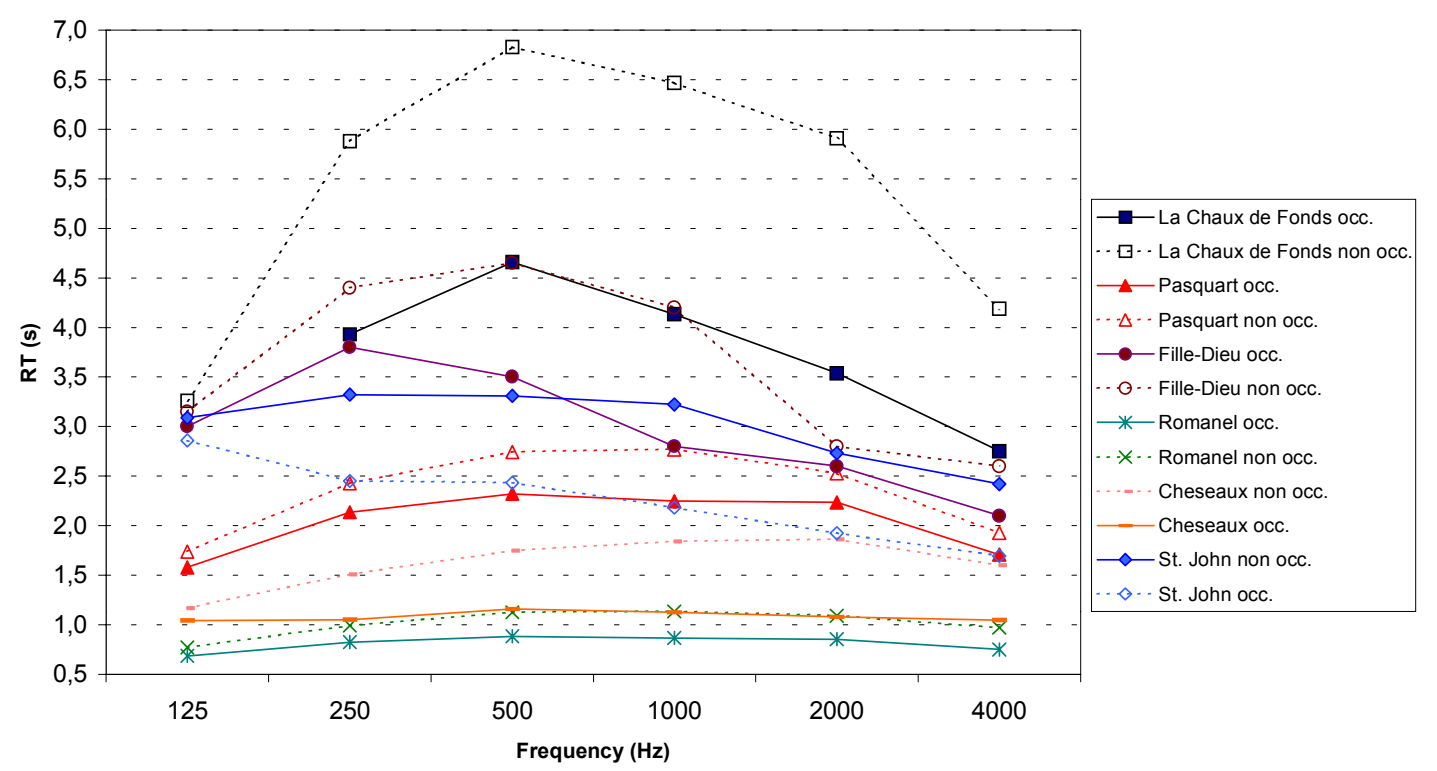

Figure 2. Variations in the reverberation time values in churches (occupied and unoccupied conditions). 


\subsubsection{Increased sound absorption due to the audience}

The reduction in the reverberation time values comes primarily from the increased sound absorption brought by the audience. The value of that reduction in the reverberation time values in a church depends mainly on its volume and on the reverberation time of the unoccupied building, as well as on the number and dispersion of the persons in it.

The calculation of the additional average equivalent sound absorption by person (Apers in $\mathrm{m}^{2}$ ) can be done starting from the Sabine equation, that is:

$$
A_{\text {pers }}=\frac{0.16^{*} V}{N} *\left(\frac{1}{\text { RTocc }}-\frac{1}{\text { RTunocc }}\right)
$$

where $N$, number of persons, $V$ volume $\left(\mathrm{m}^{3}\right), R T o c c$ and $R T$ Tunocc, the average reverberation time values in the occupied and unoccupied church. For the churches sampled (excepted for Pasquart that has sound absorbent seating), the average equivalent sound absorption values $A_{\text {pers }}$ (calculated using the Sabine equation for all the sampled churches) and the optimised $A_{\text {pers }}$ ' values (calculated using the least square method, by minimization of the $\chi^{2}$ calculation-measurement for the churches sampled) are given in Table 4 and Figure 3.

Table 4. Equivalent sound absorption by person (Apers) according to frequency

\begin{tabular}{lccccccc} 
Frequency $(\mathrm{Hz})$ & 125 & 250 & 500 & $1 \mathrm{k}$ & $2 \mathrm{k}$ & $4 \mathrm{k}$ & avg. $500-1 \mathrm{k}$ \\
\hline Mean calculated values $A_{\text {pers }}\left(\mathrm{m}^{2}\right)$ & 0.24 & 0.50 & 0.56 & 0.73 & 0.76 & 0.77 & 0.64 \\
\hline Standard deviation $\left(\mathrm{m}^{2}\right)$ & 0.18 & 0.22 & 0.06 & 0.17 & 0.34 & 0.25 & 0.09 \\
\hline Optimised calculation $A_{\text {pers }}{ }^{\prime}\left(\mathrm{m}^{2}\right)$ & 0.13 & 0.53 & 0.54 & 0.73 & 0.79 & 0.87 & 0.63
\end{tabular}

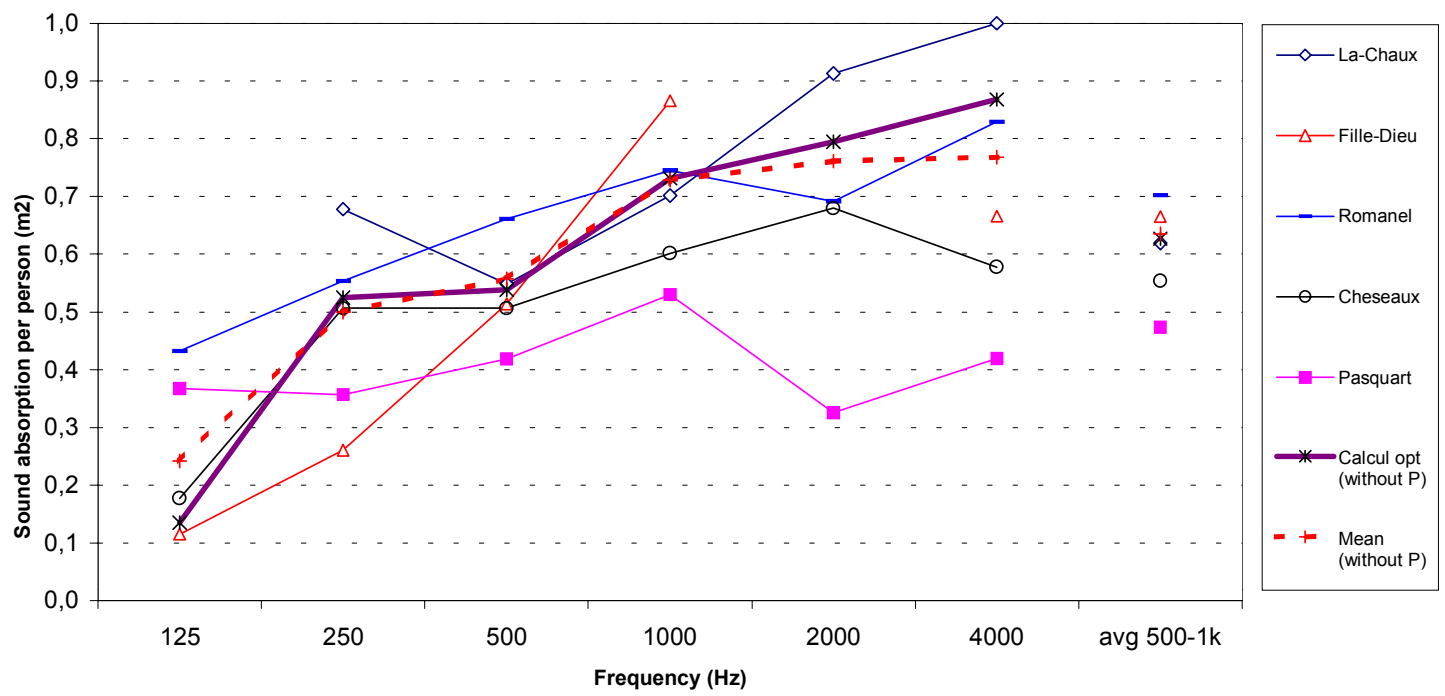

Figure 3. Sound absorption (per person) for the church audience (La-Chaux church has dispersed seating and the others have dense seating; Pasquart church has absorbent chairs, others have sound reflective pews). 
The mean sound absorption by person $\left(A_{\text {pers }}\right)$ calculated for the average reverberation time $(500-1000 \mathrm{~Hz})$ and for all the churches, equals to $0.64 \pm 0.09 \mathrm{~m}^{2}$.

When the persons are relatively grouped in a church (case of the churches FilleDieu, Cheseaux and Romanel) the sound absorption at the highest frequencies $(f>2$ $\mathrm{kHz}$ ) is about $0.7 \mathrm{~m}^{2}$. When the faithful are highly dispersed (case of La-Chaux-deFonds church) the sound absorption per person in the highest frequencies increases to approximately $0.9 \mathrm{~m}^{2}$. The standard deviation between the sound absorption values $\left(A_{\text {pers }}\right)$ calculated for each church is high. This can be explained by the strong variation of the occupation density from one church to another and maybe even by the type of clothing worn during measurements that took place both in summer and in winter.

The smaller $A_{\text {pers }}$ values found for the Pasquart church (Figure 3) were caused by the sound absorptive characteristics of its seats. The average sound absorption per person calculated in this case corresponds to the difference between the average sound absorption per person on the pews (standard situation as on the other churches) and the sound absorption of the stuffed seats.

The minimization of the differences between measured and calculated absolute values makes it possible to determine an optimised sound absorption per person which allows a satisfactory estimate of the $R T$ in all cases (the average error between the computed and the measured occupied reverberation time values is lower than 0.1 second, see Figure 4). The Sabine equation seems then sufficient to calculate the reduction in the reverberation time values given by the additional sound absorption caused by the presence of the audience.

The values obtained for the equivalent sound absorption per person are generally higher than those available in the literature for a seated person, because of the low

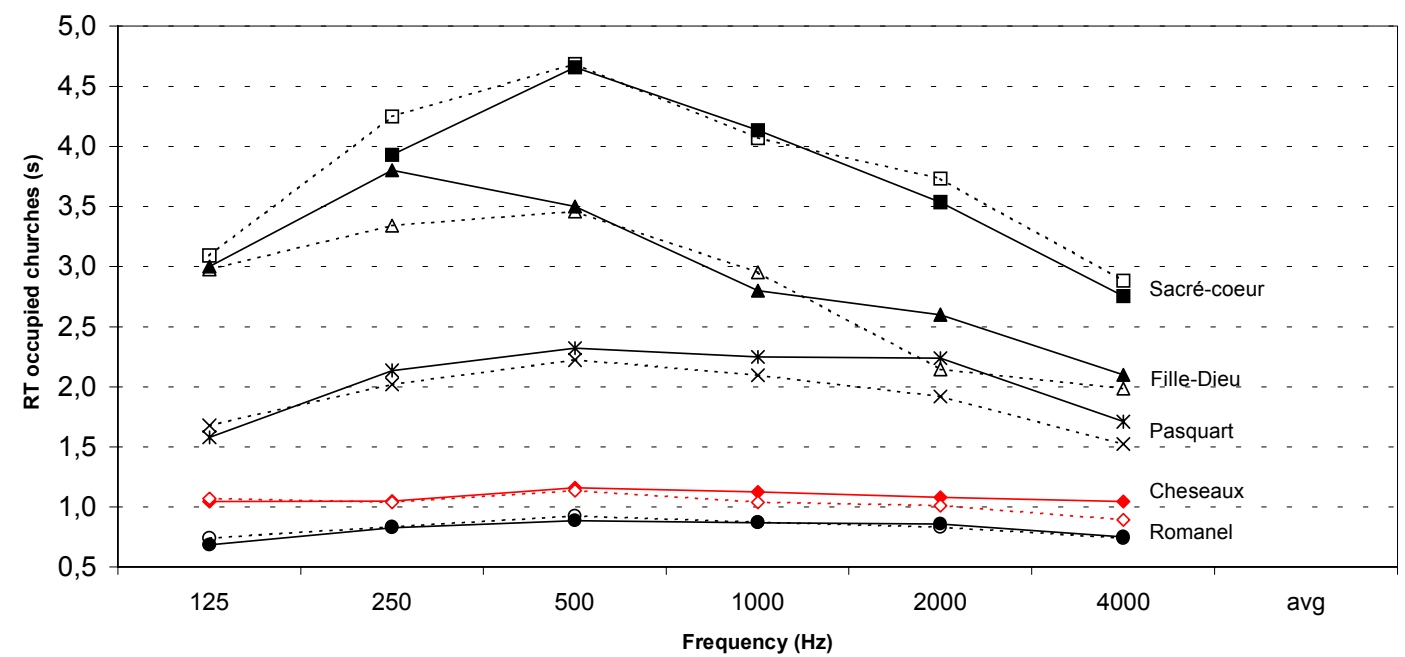

Figure 4. Reverberation Time values - measured (full lines) and calculated with optimised Apers (dotted lines) for occupied churches. 
occupation density in the occupied churches compared to values calculated using a reverberation chamber or a concert hall. The edges effect being more significant for a dispersed assembly, one could expect an increase in the equivalent sound absorption per person.

Another approach, suggested by several authors ${ }^{11-12}$, in particular for concert and opera halls, consists in defining the audience sound absorption not by person $\left(A_{\text {pers }}\right.$ in $\left.\mathrm{m}^{2}\right)$ but per unit of floor area of the building $\left(\alpha_{\text {pers }}\right)$ by considering as an additional parameter the ratio of perimeter/area of the congregation seating area ${ }^{1,2,13}$. Considering the difficulty in clearly defining these parameters in the case of church buildings, often with a very scattered seating arrangements, this later approach does not seem well adapted to these situations but seems to remain rather specific for an audience in dense seating areas (which is generally the case for theatres, concert or opera halls).

The prediction method suggested by Beranek ${ }^{11}$ for concert halls where the absorption characteristics of the seats are not known, was tested in this study, that is,

$$
R T o c c=c-d^{*} \exp (-R T u n o c c)
$$

In spite of optimisation of the parameters $c$ and $d$ for each frequency band by the method of least squares, this method does not make it possible to calculate, in a satisfactory way, the reverberation time in churches slightly occupied (deviation of \pm $0.9 \mathrm{~s}$ in particular in the 500 and $1000 \mathrm{~Hz}$ frequency bands).

\subsubsection{The effect of heating}

In summer, the temperature and humidity within a church practically do not change with the occupation (approximately 20 to $23{ }^{\circ} \mathrm{C}$ and 60 to $70 \%$ relative humidity ( $\mathrm{r} \mathrm{h}$ ) in Switzerland). In contrast, in winter, heating the church before and during the service modifies its hygrothermic conditions. In a unheated church, the temperature is about 8 to $10{ }^{\circ} \mathrm{C}$ with a relative humidity of about 60 to $70 \%$, whereas in a heated church (for the periods of occupation), the temperature goes up to $18-20^{\circ} \mathrm{C}$ and the humidity goes down to $40-50 \%{ }^{14}$. The variation in relative humidity is mainly due to the increase in temperature. With constant temperature, humidification of the air by the presence of a congregation remains weak (the increase of the relative humidity due to the audience is lower than $10 \%$ ).

In winter, the church heating system during ceremonies causes several effects favourable to the speech intelligibility values, such as:

1. A small increase in air absorption between 500 and $2000 \mathrm{~Hz}$ that involves a slight reduction in reverberation time values at these frequencies. At high frequencies $(f>2$ $\mathrm{kHz}$ ), the opposite phenomenon, with more significant values is observed (Table 5).

The absorption of the air is given by the following formula ${ }^{15}$ :

$$
A_{\text {air }}=4 m^{*} V
$$

where $V$ is volume, (in $\left.10^{3} \mathrm{~m}^{3}\right)$ and the $4 m\left(\mathrm{~m}^{-1}\right)$ the air equivalent absorption coefficient. 
For the winter climatic conditions, referred to above, the air absorption values presented in Table 5 are obtained ${ }^{9}$. The values show an increase in air absorption in the low and medium frequency bands (the values remain however low) and a reduction in the absorption at higher frequencies $(f>2 \mathrm{kHz})$. As an example, considering a church of volume $6000 \mathrm{~m}^{3}$ with a reverberation time (unoccupied) of 4 $\mathrm{s}$, the reduction in the average reverberation time by the modification of the air absorption is about $0.1 \mathrm{~s}$.

Table 5. Air absorption (4m) for winter climatic conditions $\left(\mathrm{m}^{-1}\right)^{9}$

\begin{tabular}{lccccccc} 
Frequency $(\mathrm{Hz})$ & 125 & 250 & 500 & 1000 & 2000 & 4000 & 8000 \\
\hline Non-heated church $\left(10^{\circ} \mathrm{C}, 60 \% \mathrm{r} \mathrm{h}\right)$ & 0.4 & 0.9 & 1.7 & 3.1 & 6.9 & 23.1 & 82.3 \\
\hline Heated church $\quad\left(20^{\circ} \mathrm{C}, 40 \% \mathrm{r} \mathrm{h}\right)$ & 0.5 & 1.3 & 2.4 & 3.9 & 7.4 & 22.0 & 77.5
\end{tabular}

2. Heating of the church during services also induces an increase in the speed of sound propagation that causes a reduction in the building reverberation time. Reverberation time is given by the following formula ${ }^{8}$ :

$$
R T=\frac{55.3 * V}{c(t) * A}
$$

where $c(t)$ is the velocity of the sound propagation in the air at the temperature $t$ (in $\left.{ }^{\circ} \mathrm{C}\right)$ given by:

$$
c(t)=20.04 * \sqrt{273.16+t}
$$

The ratio of the reverberation time $(R T)$ of a room at two different temperatures $(t)$ is then equal to the inverse ratio of the velocities of the sound propagation $(c)$ at these two temperatures:

$$
\frac{R T(t 1)}{R T(t 2)}=\frac{c(t 2)}{c(t 1)}
$$

Considering typical temperatures avlues of $t 1=20^{\circ} \mathrm{C}$ and $t 2=10^{\circ} \mathrm{C}$, yields:

$$
R T\left(20^{\circ} \mathrm{C}\right)=c\left(10^{\circ} \mathrm{C}\right) / c\left(20^{\circ} \mathrm{C}\right) * R T\left(10^{\circ} \mathrm{C}\right)=337 / 343 * R T\left(10^{\circ} \mathrm{C}\right)=0.98 * R T\left(10^{\circ} \mathrm{C}\right)
$$

that is, a decrease of approximately $2 \%$ in the reverberation time values as a result of the temperature increase due to normal winter heating conditions in a typical church.

Considering a church with a reverberation time of $4 \mathrm{~s}$, the reduction in reverberation time as a result of increasing the velocity of the sound propagation in the air, by heating is about $0.1 \mathrm{~s}$ (Table 6).

For a church of volume $6000 \mathrm{~m}^{3}$ with a reverberation time (unoccupied) of $4 \mathrm{~s}$, the 
two effects induced by heating (the increase in air absorption coefficient and speed of sound) result in a reduction in the reverberation time at medium frequencies of about 0.1 to $0.2 \mathrm{~s}$ (Table 6).

Table 6. Effects of church heating on reverberation time

(as a result of the increase in sound absorption coefficient of the air, and the speed of sound propagation)

\begin{tabular}{llllllll} 
Frequency & $(\mathrm{Hz})$ & 125 & 250 & 500 & 1000 & 2000 & 4000 \\
\hline$R T$ Unoccupied mean & $(\mathrm{s})$ & 2.7 & 4.2 & 4.7 & 4.5 & 3.7 & 2.9 \\
\hline$\Delta R T$ air absorption & $(\mathrm{s})$ & 0.00 & -0.04 & -0.09 & -0.10 & -0.04 & 0.06 \\
\hline$\Delta R T$ speed of sound c & $(\mathrm{s})$ & -0.05 & -0.07 & -0.08 & -0.08 & -0.06 & -0.05 \\
\hline$\Sigma \Delta R T$ heating & $(\mathrm{s})$ & -0.05 & -0.12 & -0.17 & -0.17 & -0.11 & 0.01
\end{tabular}

3. Church heating during services sometimes induces a downward bending of the sound rays, due to a positive temperature gradient in the space with height. When the church is empty (with little or no heating), the positive variation in temperature with height is insignificant. This is also the case $\left(<1^{\circ} \mathrm{C}\right)$ with heating under the pews (with or without convector) or under floor heating. Hot-air heating can, however, generate a more significant variation in temperature (the temperature near the ceiling can be 5 ${ }^{\circ} \mathrm{C}$ higher than near the floor). In this case, the bending downward of the sound rays contributes to a better sound distribution within the congregation.

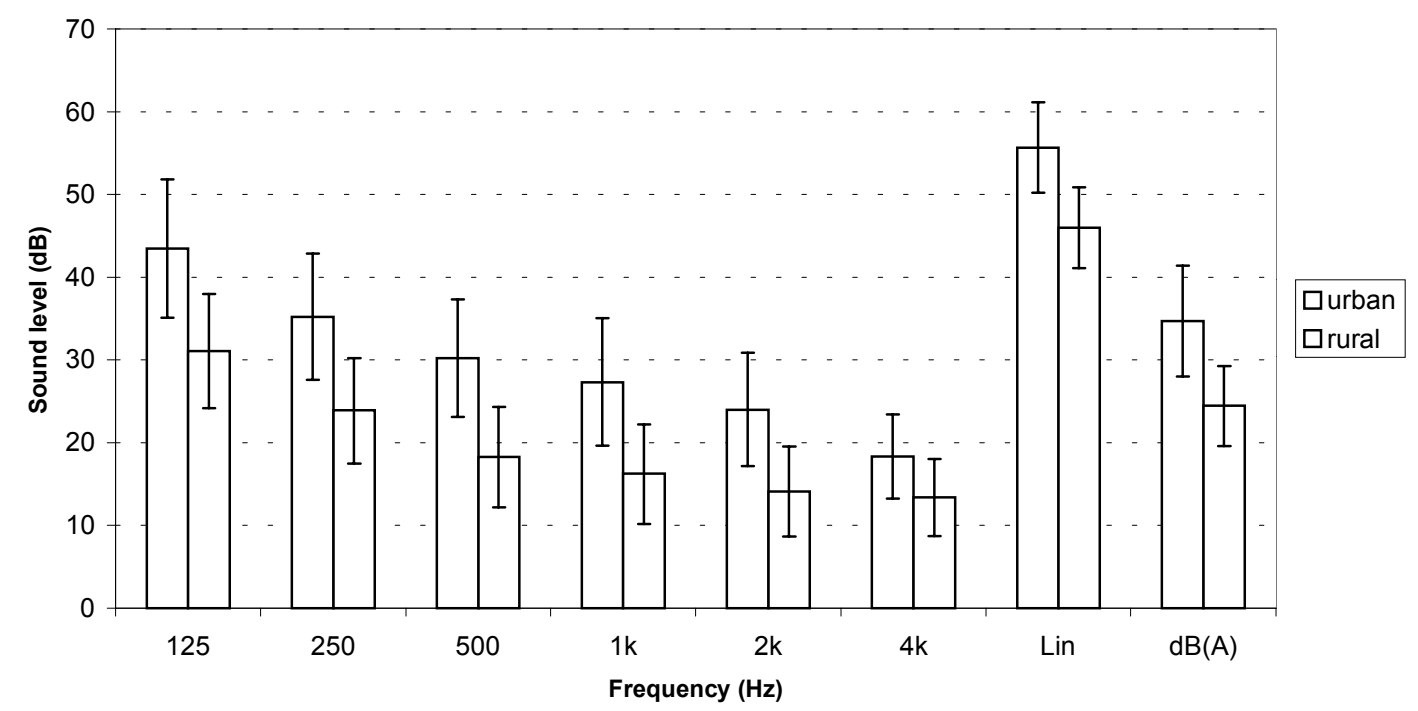

Figure 5. Background noise in churches for two types of environments: Rural and Urban (mean values \pm 1 standard deviation for 44 Swiss churches). 


\subsection{3 - Background noise}

In a preceding study ${ }^{16}$, the background noise in 44 unoccupied churches was measured and analysed according to the surrounding environment (urban or rural) of the churches (see Table 7 and Figure 5). The equivalent sound levels and $\mathrm{S} / \mathrm{N}$ were also measured during and after religious services (see Table 8).

It was noted that the background noise increases by $10 \pm 4 \mathrm{~dB}$ when the church is occupied. When the churches are unoccupied, the signal-to-noise ratio is higher than is necessary ( 25 to $35 \mathrm{~dB}$ ). When the churches are occupied, the signal-to-noise ratio remains generally sufficient $(>15 \mathrm{~dB})$ not to interfere with speech intelligibility. In spite of the systematic use of sound systems in large churches or in those with a high background noise, the ratio $S / N$ can be insufficient in certain particular cases (for instance $14 \mathrm{~dB}$ at La-Chaux-de-Fonds church). This can be due to a low source sound level (bad adjustment or absence of a sound system) or to a high background noise made by the congregation (for instance, measurements in certain positions within Lausanne cathedral could not be carried out or the results were strongly influenced by coughing in the congregation).

Table 7. Mean values of background noise in 44 Swiss churches [16]

\begin{tabular}{lcccc} 
Church environment & \multicolumn{2}{c}{ Mean values $(\mathrm{dB})$} & \multicolumn{2}{c}{ Standard deviation $(\mathrm{dB})$} \\
\cline { 2 - 5 } & $L_{\text {Aeq }}(20 \mathrm{~s})$ & $L_{e q}(20 \mathrm{~s})$ & $L_{\text {Aeq }}(20 \mathrm{~s})$ & $L_{e q}(20 \mathrm{~s})$ \\
\hline Urban & 35 & 56 & 7 & 5 \\
Rural & 23 & 46 & 4 & 5 \\
\hline$\Delta$ (= urban - rural) & 12 & 10 & 3 & 0
\end{tabular}

Table 8. Equivalent sound levels $\left(L_{A e q}(20 s)\right)$ measured during and after religious services in $\mathrm{dB}$

\begin{tabular}{llcccc}
\hline $\begin{array}{l}\text { Church } \\
\text { Denomination } \\
\text { Environment }\end{array}$ & & $\begin{array}{c}\text { La-Chaux } \\
\text { Catholic } \\
\text { Urban }\end{array}$ & $\begin{array}{c}\text { Pasquart } \\
\text { Protestant } \\
\text { Urban }\end{array}$ & $\begin{array}{c}\text { Cheseaux } \\
\text { Protestant } \\
\text { Rural }\end{array}$ & $\begin{array}{c}\text { Romanel } \\
\text { Protestant } \\
\text { Rural }\end{array}$ \\
\hline Distance to sound source (m) & & 30 & 10 (lateral) & 8.5 & 6 \\
\hline Speech (man) & with sound system & $55-59$ & $60-67$ & - & - \\
Speech (woman) & with sound system & $53-57$ & $57-66$ & - & - \\
Speech (man) & without sound system & - & $43-50$ & $56-63$ & $54-60$ \\
Speech (woman) & without sound system & - & $42-48$ & - & $52-55$ \\
\hline Background noise & during speech & $40-45$ & $35-43$ & $32-39$ & $30-38$ \\
Background noise & unoccupied & 32 & 29 & 25 & $21-25$ \\
\hline S/N occupied church & man & 14 & 25 & 25 & 23 \\
S/N unoccupied church & man & 25 & 35 & 35 & 34 \\
\hline
\end{tabular}


In winter, many churches often need heating before and during religious services. Depending on their design, heating systems can generate considerable noise within the church. For instance, in Lausanne cathedral, background noise in the congregation changes from $31 \mathrm{~dB}(\mathrm{~A})$ in the absence of heating, to the high $40 \mathrm{~s}$ or even lower $50 \mathrm{~s} \mathrm{~dB}(\mathrm{~A})$ depending on the heating system in operation ${ }^{17}$.

\subsubsection{Sound attenuation within the congregation area}

In general for the whole group of churches tested, improvement in speech intelligibility $(\Delta S T I)$ is hardly correlated with distance to the main sound source. However, in each particular church a trend can be visible for the sound level within the congregation area. As a typical example, sound level attenuation with distance is presented in Figure 6 for a particular church, with and without the use of a sound system.

The variation of reverberation time values due to occupation (and possibly to heating) involves an attenuation of the sound level in the reverberant field that can be expressed approximated by:

$$
\Delta L(d B) \approx 10 * \log \left(R T_{\text {occ }} / R T_{\text {unocc }}\right)
$$

According to the measurement $R T$ values, and the formula above, the decrease in reverberant sound level should be between 1.1 and $1.9 \mathrm{~dB}$. According to our SPL measurements (see Figure 6 as a typical example), the additional attenuation $(\Delta L)$ with distance due to the congregation, varies from 0.5 and $2.6 \mathrm{~dB}(\mathrm{~A})$. It should be noted that measured values relate to the total sound level (direct + reverberant). For distances

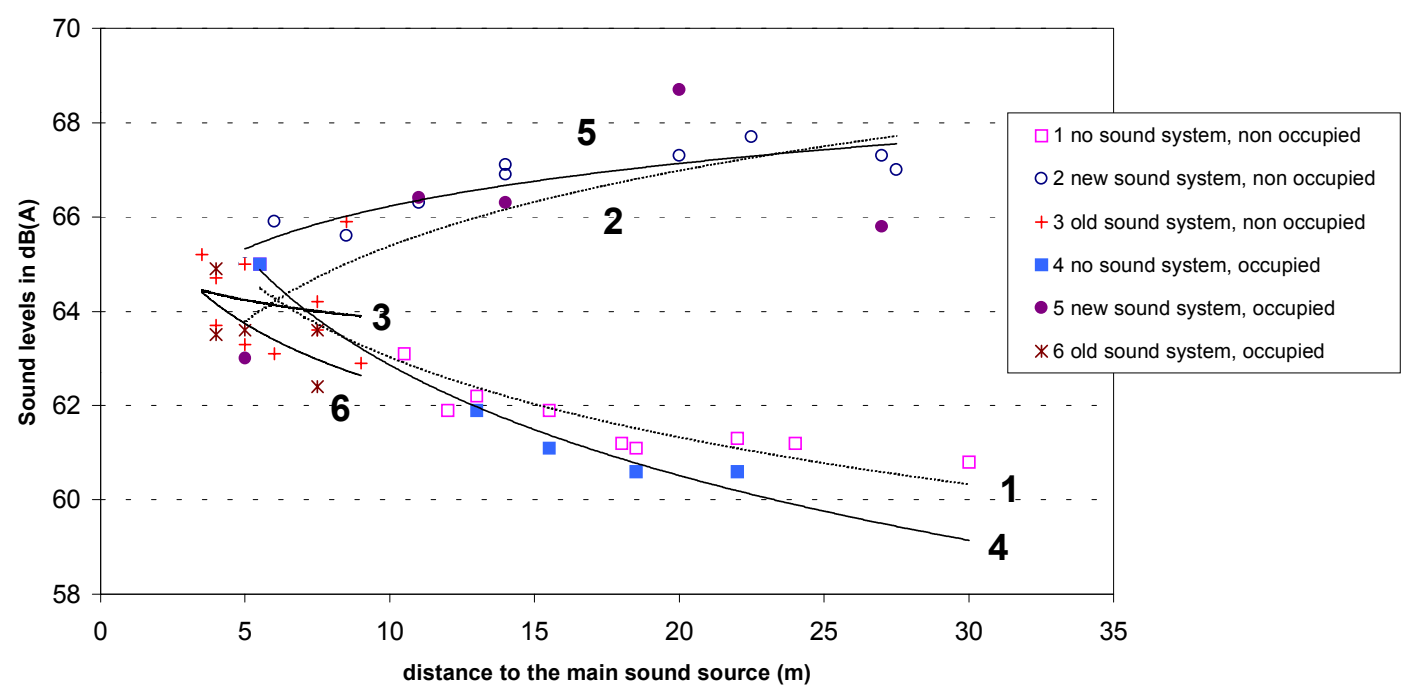

Figure 6. Church La-Chaux-de-Fonds, $\mathrm{CH}$ - Sound levels variation with distance to the main sound source. 
definitely larger than the equivalent room radius, the decrease becomes very weak because the reverberant field becomes dominant. Lottermoser also noted in 1952 that the reduction in the sound level in the presence of the congregation was only approximately $3 \mathrm{~dB}$ at $25 \mathrm{~m}$ from an organ, and in an elevated position compared to the congregation ${ }^{18}$. More recently, Beranek showed that the Strength $(G)$ decreased, between an empty and full concert hall, by approximately $2 \mathrm{~dB}$ at intermediate frequency bands ${ }^{22}$.

The decrease with the distance for the early sound level (direct sound and first reflections), influential for speech intelligibility, is however definitely more significant. In free field conditions, the attenuation of the direct sound within an audience reaches $30 \mathrm{~dB} / 100 \mathrm{~m}$ at $500 \mathrm{~Hz}(37 \mathrm{~dB} / 100 \mathrm{~m} \text { at } 2 \mathrm{kHz})^{19}$.

\subsection{Calculation Models}

Two models (theoretical and empirical) can be proposed to determine the variation of speech intelligibility, objectively measured by the STI, with church occupancy, based on the main effects present. For this calculation, the $2 \mathrm{kHz}$ frequency band was chosen for a representative single-number $R T$, not only because it is the most important with regard to speech intelligibility but also because it was shown to have the best correlation values of all the average $R T$ hypotheses tested.

\subsubsection{Theoretical model}

Speech transmission from a speaker to a listener is mainly affected by reverberation and background noise. These two effects are well quantified by the Modulation Transfer function $(\mathrm{MTF})^{20}$. By definition the $S T I$ can be given by ${ }^{9,20}$ :

$$
S T I=\frac{\operatorname{Seff}+15}{30}=\frac{10 * \lg \left(\frac{m}{1-m}\right)+15}{30} \quad \text { where, }
$$

Seff - Mean value of the effective signal-to-noise (dB);

$m$ - Modulation Transfer Function, and

$$
m(f)=\frac{1}{\sqrt{1+\left(2 \pi \mathrm{f} \frac{R T}{13.8}\right)^{2}}} * \frac{1}{\left(1+10^{-S / 10}\right)} \quad \text { (1) where } S \text { stands for the } \mathrm{S} / \mathrm{N} \text { ratio }(\mathrm{dB})
$$

In Equation 1 the first term determines the contribution of the reverberation time and the second quantifies the effect of the background noise. Therefore, the variation in the $S T I$ values $(\triangle S T I)$ between an occupied and unoccupied church can be expressed as function of the MTF by:

$$
\Delta S T I=S T I\left(m^{\prime}\right)-S T I\left(m^{\prime \prime}\right)=\frac{1}{3} * \lg \left(\left(\frac{m^{\prime}}{1-m^{\prime}}\right) *\left(\frac{1-m^{\prime \prime}}{m^{\prime \prime}}\right)\right)
$$


where $m^{\prime}$ and $m^{\prime \prime}$ stand for the Modulation Transfer Function (MTF) respectively in an occupied and in an unoccupied church.

a) Effect of the reduction in the reverberation time

If the background noise is neglected (suppression of the second term in the Equation 1), the MFT becomes:

$$
m(f)=\frac{1}{\sqrt{1+\left(\frac{2 \pi f \cdot R T}{13.8}\right)^{2}}}=\frac{1}{\sqrt{1+g \cdot R T^{2}}}
$$

with $g=\left(\frac{2 \pi f}{13.8}\right)^{2}, f=$ modulation frequency and $R T$ the reverberation time.

Note that for an average modulation frequency $f=2.8 \mathrm{~Hz}$, the parameter $g=$ 1.6252. Then, the following expression can be written:

$$
\frac{m}{1-m}=\frac{1}{\sqrt{1+g \cdot R T^{2}}-1}
$$

Thus, the variation in the $S T I$ values given by the variation in the reverberation time values can be expressed by:

$$
\Delta S T I=\frac{1}{3} * \lg \left(\frac{\sqrt{1+g\left(R T_{\text {unoccup }}\right)^{2}}-1}{\sqrt{1+g\left(R T_{\text {occup }}\right)^{2}}-1}\right)
$$

In situations where a sound system is used, this theoretical model allows a very good evaluation of the variation of the $S T I\left(R^{2}=0.95\right.$ for $R T(2 \mathrm{kHz})$ ) (see Figure 7). In these cases, the effect of the background noise is negligible $(S / N>15 \mathrm{~dB})$ and only the effect of the reverberation seems important.

In the absence of a sound system, this model, based only on reverberation time, provides a poorer evaluation of the variation of the $S T I\left(R^{2}=0.77\right.$ for $\left.R T(2 \mathrm{kHz})\right)$. It systematically over-estimates the improvement of speech intelligibility (the calculated STI is too high of approximately $0.034 \pm 0.008$ ). The field measurements carried out highlight the fact that without a sound system the background noise can disturb intelligibility in some cases. This can explain the over-estimation of the model based only on reverberation time values. This over-estimation can be corrected by the use of a specific constant that could also be interpreted as a reduction in the $\mathrm{S} / \mathrm{N}$ ratio. With an average $f=2.8 \mathrm{~Hz}$, the variation of the $S T I$ can be written:

$$
\Delta \mathrm{STI}=\frac{1}{3} * \lg \left(\frac{\sqrt{1+1.6252 *\left(\mathrm{RT}_{\text {unoccup }}\right)^{2}}-1}{\sqrt{1+1.6252 *\left(\mathrm{RT}_{\text {occup }}\right)^{2}}-1}\right)-0.034
$$

b) Effect of the reduction in the signal-to-noise ratio

The presence of an audience increases room background noise and increases the reduction of sound level with distance. These variations of signal-to-noise ratio 
induce a potential modification of the STI that can be modelled theoretically. If the reverberation time is kept constant, the first term in the definition of MTF (Equation 1) becomes constant (lets call it $K$ and use a $K \approx 0.2$ for $R T=4 \mathrm{~s}$ ) and the MFT becomes:

$$
\begin{aligned}
& \mathrm{m}=\frac{\mathrm{K}}{1+10^{-\mathrm{S} / 10}} \text { with } S=\text { ratio } S / N(\text { limited to values between }-15 \text { to } 15 \mathrm{~dB}), \\
& \text { then } \frac{\mathrm{m}}{1-\mathrm{m}}=\frac{\mathrm{K}}{1-\mathrm{K}+10^{-\mathrm{S} / 10}} \approx \frac{0.2}{0.8+10^{-\mathrm{S} / 10}}
\end{aligned}
$$
by:

Thus, the variation in $S T I$ values given by variation in $S / N$ values can be expressed

$$
\begin{aligned}
& \Delta \mathrm{STI}=\frac{1}{3} * \lg \left(\frac{1-\mathrm{K}+10^{- \text {Sinoccup } / 10}}{1-\mathrm{K}+10^{- \text {Soccup } / 10}}\right) \\
& \approx \frac{1}{3} * \lg \left(\frac{0.8+10^{- \text {Sinoccup } / 10}}{0.8+10^{- \text {Soccup } / 10}}\right) \text { for } R T=4 \mathrm{~s}
\end{aligned}
$$

According to the field measurement results in this study (see Table 8), the signalto-noise ratios generally exceed $15 \mathrm{~dB}$ in occupied and unoccupied churches. Occupation does not appear to involve any modification of the STI in these cases.

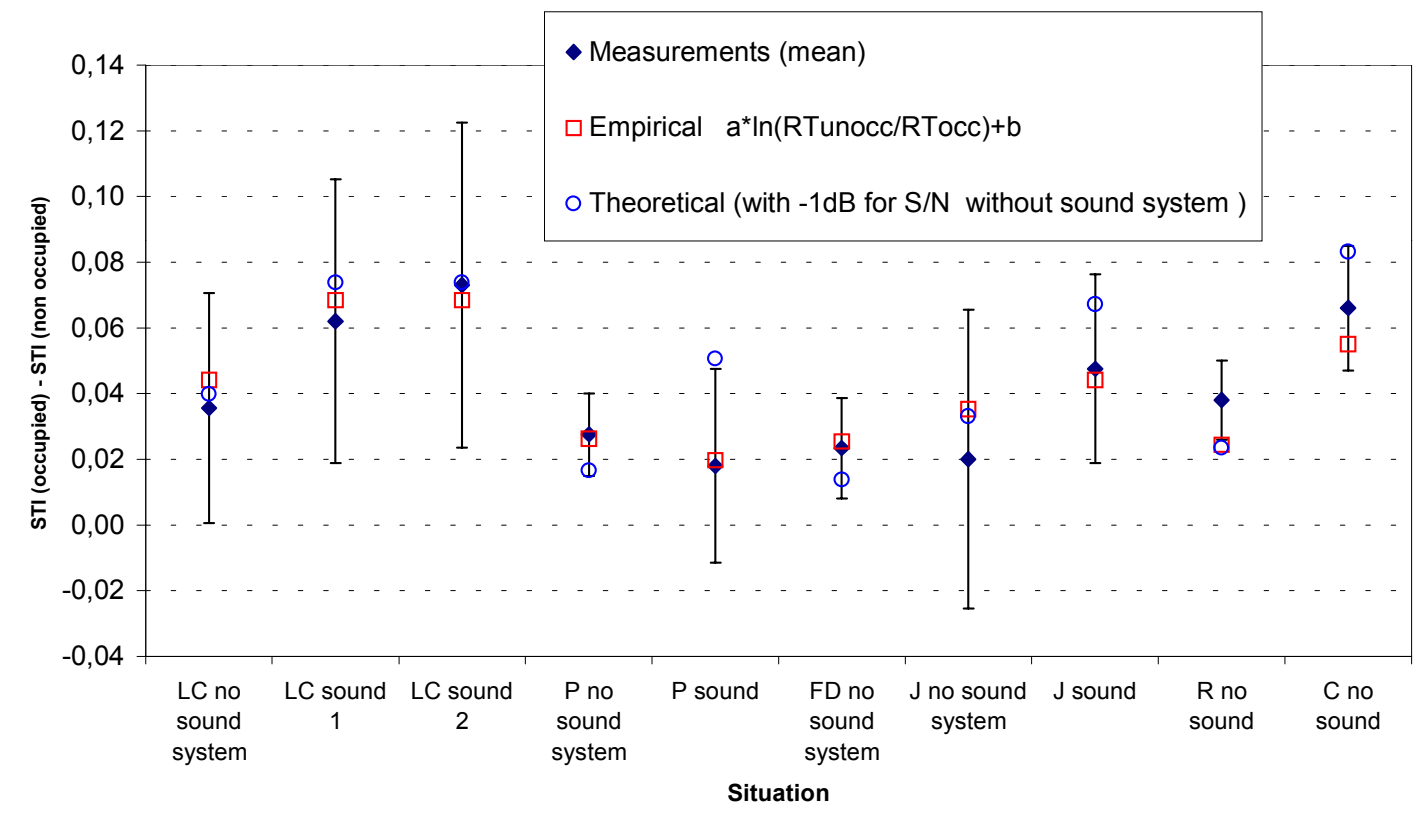

Figure 7. Comparison between measured, theoretically predicted (Equation 2A) and empirically formulated $\triangle S T I$ values, for occupied churches, at $R T(2 \mathrm{kHz})$. (LA - La Chaux, P - Pasquart, FD - Fille-Dieu, J - St. John, $\mathrm{R}$ - Romanel, C - Cheseaux). 
In one case however (La-Chaux church), background noise increases sufficiently with the number in the congregation, to decrease the $\mathrm{S} / \mathrm{N}$ ratio to less than $15 \mathrm{~dB}$. In this case $\left(\mathrm{S}_{\text {occup }}=14 \mathrm{~dB}\right)$, the contribution of background noise to the variation of speech intelligibility is, according to the theoretical model (Equation 3)

$$
\Delta S T I=-0.001 .
$$

This negligible value is strongly affected by the reverberation time value used that is rather high $(R T=4 \mathrm{~s})$ and that is significant for speech intelligibility. In churches a small decrease in the $\mathrm{S} / \mathrm{N}$ has only a very small effect if the reverberation time is high. The results for the theoretical model (with this correction) are presented in Figure 7.

\subsection{2 - Empirical model}

From the results obtained for the field measurements reported in this study, an empirical approach can be stated that allows a simpler formulation than the above theoretical models. The field results showed that the principal factor influencing speech intelligibility (STI) was the variation of reverberation time (the distance factor is not very significant). As the climatic parameters (temperature and relative humidity) were not measured in situ, the proposed logarithmic model is simply of the type:

$$
\Delta S T I=a * \ln \left(R T_{\text {occ }} / R T_{\text {unocc }}\right)+b
$$

where the parameter $a$ takes into account the contribution of variation of reverberation time, and the parameter $b$ gathers the other diverse contributions.

The optimisation of these two parameters (for medium size churches) gives the following formula:

$\Delta S T I=0.276 * \ln \left(R T_{\text {unoccup }(2 k H z)} / R T_{\text {occ }(2 k H z)}\right)-0.052$ with a sound system $\left(R^{2}=0.96\right)$, and

$$
\Delta S T I=0.102 * \ln \left(R T_{\text {unoccup }(2 k H z)} / R T_{\text {occ }(2 k H z)}\right) \text { without PA }\left(R^{2}=0.55\right) .
$$

These formulae were not tested for very large churches and may be not valid beyond the range of the data. The values obtained by these formulae are presented in Figure 7.

Determination of the value for the parameter $a$, for situations with sound systems, gives a higher value than for a theoretical condition without background noise $(a=$ 0.190 according to ${ }^{20}$ ). The reduction of the additional $R T$ induced by the PA system (using loudspeakers with strong directivity oriented to the congregation area) could however explain the higher slope obtained empirically with PA.

If one considers Early Decay Time (EDT) instead of the Reverberation Time, the theoretical value of $a$ is 0.216 what would result in an increase in STI of 0.15 , by 
reduction of reverberation time by a factor of 2. (This last value was highlighted in a study undertaken in university classrooms ${ }^{21}$ ). In these particular cases (low specific volume and rather high reverberation time), occupancy can affect the STI considerably, from 0.47 to 0.76 in unoccupied classrooms, 0.61 to 0.77 with half occupancy and 0.65 to 0.82 in fully occupied.

\section{5 - SUMMARY}

Measurements were carried out in six churches with and without occupancy (mean volume of $4385 \mathrm{~m}^{3}$ and mean occupancy of 117 persons) to test the effect of occupancy on $S T I$ values. The results show that occupancy causes a mean increase in speech intelligibility of $\triangle S T I\left(S T I_{\text {occup }}-S T I_{\text {unoccup }}\right)$ of 0.050 with the use of a public address system (PA) and 0.035 without a PA. This increase is caused mainly by the reduction in room reverberation time, due to the additional sound absorption caused by the presence of people. The variations in the speech intelligibility values with occupancy can be predicted in occupied and unoccupied churches (mean error $\Delta S T I<$ 0.007 ) by empirical formulae based on $R T$

$$
\begin{aligned}
& \left.\Delta S T I=0.276 * \ln \left(R T_{\text {unoccup }(2 k \mathrm{~Hz})} / R T_{\text {occ }(2 \mathrm{kHz}}\right)\right)-0.052 \text { with a PA }\left(R^{2}=0.96\right), \text { and } \\
& \Delta S T I=0.102 * \ln \left(R T_{\text {unoccup }(2 \mathrm{kHz})} / R T \text { occ }(2 \mathrm{kHz})\right. \\
& ) \text { without a PA }\left(R^{2}=0.55\right) .
\end{aligned}
$$

The reduction of $R T$ caused by the PA system (using loudspeakers with strong directivity oriented towards the congregation area) could explain the high slope obtained in the above empirical model with PA (higher than the values expected theoretically).

The reduction in reverberation time in an occupied church depends on its volume and unoccupied reverberation time, as well as on the number and dispersion of the people on it. The mean sound absorption per person $\left(A_{\text {pers }}\right)$ calculated for the average reverberation time $(500-1000 \mathrm{~Hz})$ for each church, is equal to $0.64 \pm 0.09 \mathrm{~m}^{2}$.

The decrease in the $S / N$ ratio (due to the background sound level increase by the presence of people, by increased sound level decrease with distance in the congregation area, or by poor directivity and orientation of the sound sources) could reduce the $S T I$ gain in particular cases. However, these effects are generally negligible.

The variations of humidity and temperature caused by the congregation and by heating cause a small change in $R T$ values (less than $0.2 \mathrm{~s}$ ) and generally a negligible change in $S T I$ values.

\section{REFERENCES}

1. Bradley, J. "The sound absorption of occupied auditorium seating", J. Acoust. Soc. Am., 1996, 99(2), 990-995.

2. Bradley, J. "Measuring and predicting the effect of an audience", 124th Acoust. Soc. Am. meeting 1992, New Orleans. 
3. Arau, H. "Variation of the reverberation time of places of public assembly with audience size", Building Acoustics, 1997, 4(2), 87-97.

4. Schultz, T. and Watters, B. "Propagation of sound across audience seating", J. Acoust. Soc. Am., 1964, 35(5), 885-896.

5. Mommertz, E. "Einige Messungen zur streifenden Schallausbreitung über Publikum und Gestühl", Acustica, 1993, 79, 42-52.

6. Davies, W. and Lam, Y. "New attributes of seat dip attenuation", Applied Acoustics, 1994, 41, 1-23.

7. LoVetri, J., Mardane, D. and Soulodre, G. "Modelling of the seat dip effect using the finite-difference time domain method", J. Acoust. Soc. Am., 1996, 100(4), 2204-2212.

8. Bradley, J. "Some further investigations of the seat dip effect", J. Acoust. Soc. Am., 1991, 90(1), 324-333.

9. EN 60268-16, "Evaluation objective de l'intelligibilité de la parole au moyen de l'indice de transmission de la parole", Commission Electrotechnique Internationale, 1998.

10. Carvalho, A. "The significance of the Church Occupancy in the RASTI values in a Catholic Church", Congrès Français d'Acoustique CFA2000, 2000, Lausanne, 477-480.

11. Beranek, L. "Concert and Opera Halls. How they sound." Acoust. Soc. Am., 1996, New York.

12. Barron, M. "Auditorium Acoustics and Architectural Design", E\&FN Spon, London, 1993.

13. Bradley, J. "Predicting the absorption of pew cushions", 124th Acoust. Soc. Am. meeting 1992, New Orleans.

14. Hungerbühler, E. "Dimensionierung, Sanierung und Betrieb von Elektroheizungen in Kirchen", I. Ravel, Bern, 1994.

15. PrEN 12354-6 (4th draft), "Estimation of acoustic performance of buildings from the performance of elements. Part 6: Sound absorption in enclosed spaces", Brussels, 2000.

16. Desarnaulds, V., Bossoney, S. and Eggenschwiler K. "Studie zur Raumakustik von Schweizer Kirchen", DAGA 1998, Zürich, 710-711.

17. Desarnaulds, V. "Mesurages des bruits de ventilation dans la cathédrale de Lausanne pour différents régimes de fonctionnement", Rapport No $1704 \mathrm{du}$ Bureau ing. G. Monay, 1995, Lausanne.

18. Lottermoser, W. "Nachhalzeiten in Barockkirchen", Acustica, 1952, 2, 109111.

19. Ahnert, W. and Steffen, F. "Beschallungtechnik. Grundlagen und Praxis", 1993.

20. Houtgast, M. and Steeneken, H. "The modulation transfer function in room acoustics", Brüel\&Kjaer Technical Review, 1985, 3, 3-12.

21. Hodgson, M. "Experimental investigation of the acoustical characteristics of university classrooms", J. Acoust. Soc. Am., 1999, 106(4), 1810-1819. 
22. Beranek, L. "Relation of acoustical parameters with and without audience in concert halls and a simple method for simulating occupied state", J. Acoust. Soc. Am., 2001, 109(3), 1028-1042. 